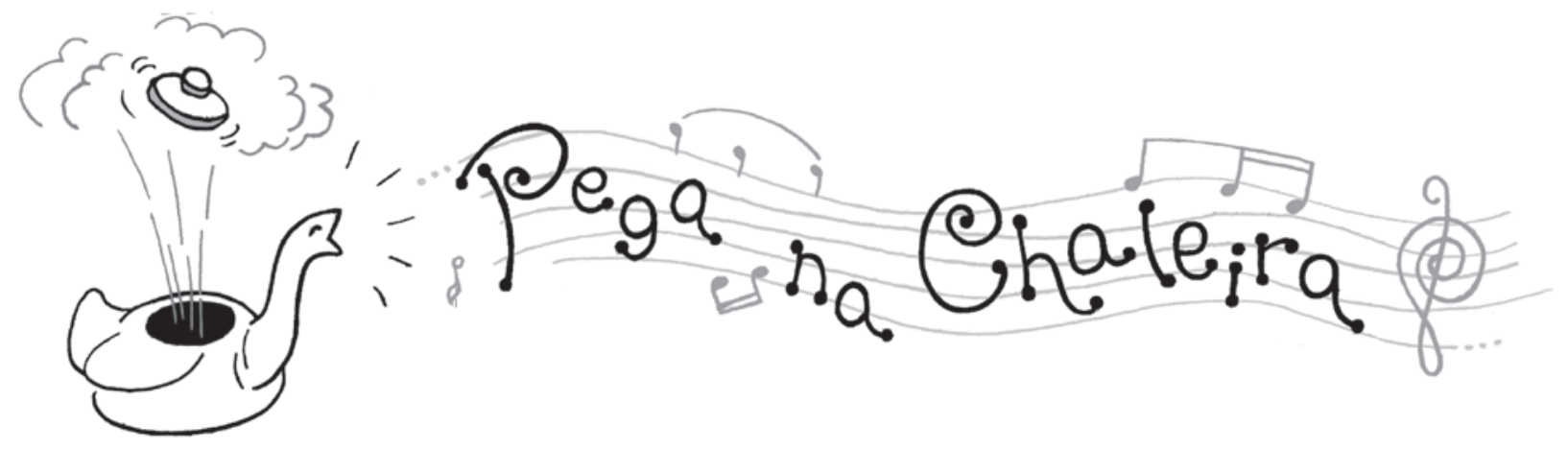

RESENHAS - "PEGA NA CHALEIRA"

\title{
Los caminos de la música, Europa y Argentina: una iniciativa editorial a imitar
}

Fátima Graciela Musri (Universidad Nacional de San Juan, San Juan, Argentina) gmusri@hotmail.com

Resumen: Reseña del libro Los caminos de la música. Europa y Argentina de Pablo BARDIN, Melanie PLESCH, Pola SUÁREZ URTUBEY, Federico MONJEAU, Pablo KOHAN, Pablo GIANERA. Jujuy : EdiUnju (Editorial de la Universidad Nacional de Jujuy), 2008, $227 \mathrm{pp}$.

Palabras-clave: Música argentina; música académica; vanguardias; tango; literatura.

Los caminos de la música, Europa y Argentina: an editorial initiative to be followed

Abstract: Review of the book The paths of the music. Europe and Argentina of Pablo BARDIN, Melanie PLESCH, Pola SUÁREZ URTUBEY, Federico MONJEAU, Pablo KOHAN, Pablo GIANERA. Jujuy : EdiUnju (University Press of Jujuy), 2008, $227 \mathrm{pp}$.

Keywords: Argentine music; art music; avant-garde; tango; literature.

Este libro es resultado de una conjunción de actos generosos en favor de la divulgación del conocimiento musical. La Fondazione Spinola (Génova) donó los artículos que contiene al Mozarteum filial Jujuy, en ocasión de cumplir este último su $25^{\circ}$ aniversario. La Universidad Nacional de Jujuy se hizo cargo de la edición y publicación del volumen, terminado a fines de 2008. Cabe valorar muy positivamente esta iniciativa y felicitar por ello a las tres instituciones involucradas.

Federico Spinola en el "Prólogo", destaca el empeño de estas instituciones por valorizar la llamada música clásica occidental, a la que este libro realiza algunos valiosos aportes relativos a la Argentina. En la "Introducción", suscrita por la Comisión Directiva del Mozarteum Jujuy, se explica que los autores fueron convocados para escribir acerca de un eje temático común: "el encuentro de Europa y América a partir de la música" y que la compilación, muy inclusiva, abre oportunidades a nuevas investigaciones.

Pablo Bardin fue el encargado de la presentación y de proponer los temas a sus colegas, en consenso con los coordinadores del Mozarteum filial Jujuy. Bardin escribió el solicitado artículo de presentación, donde reseñó acontecimientos histórico-musicales que justifican y valorizan los aportes europeos a la música de Argentina desde épocas prehispánicas hasta la actualidad. 
Su extenso artículo de treinta y nueve páginas titulado "La influencia de la música europea sobre los argentinos" (p. 17-53) contiene una profusión de datos relativamente organizados por etapas, aunque escasamente contextualizados socio-culturalmente, donde el autor hizo acopio de información de la bibliografía citada y de la obtenida en su importante carrera dedicada a la difusión mediática de la música clásica. Debemos señalar no obstante, algunas aseveraciones erróneas, ya corregidas en recientes investigaciones, entre ellas acerca de la llegada de compañías de ópera al interior (p. 41) o de la existencia de orquestas sinfónicas provinciales en la primera mitad del siglo XX.

Las partes de su artículo se subtitulan: "La época colonial" y "El siglo XIX". Faltan subtítulos para las dos etapas finales, el siglo XX y la actualidad, que son referidos allí en relación con la formación del repertorio -sobre todo en música de concierto y ópera-, y con la cita de eventos principales y figuras de compositores relevantes en la circulación metropolitana de la música. No se exponen los supuestos epistemológicos sobre los que se basa la redacción, pero se evidencia la idea de que la afición creciente y la formación del gusto por la música académica occidental serían la meta cultural de los países latinoamericanos. Es llamativo que en el tratamiento de los aportes de una cultura a otra no se hayan tematizado los conceptos de recepción, mediaciones, identidades $u$ otros provenientes del pensamiento post-colonial. En el escrito, en tanto, Argentina aparece como un país que fue "buen alumno" de Europa.

Bardin comienza con apreciaciones sobre la formación demográfica de los países latinoamericanos, la que tuvo un carácter aluvional proveniente de la conquista y la inmigración no sólo europea sino también asiática. Su explicación se posiciona en la antigua teoría del crisol de razas, que sostiene la natural integración étnica de los diferentes estratos sociales a través de las generaciones, enfoque ya discutido y moderado desde otras perspectivas críticas. En su punto de vista están ausentes los conflictos y los desplazamientos culturales ocurridos desde la conquista $y$, por el contrario, Bardin asevera que: "el mestizaje [entre aborígenes y colonos] se realiza con naturalidad" (p.17) y que el imperio incaico fue la "matriz en la cual se volcará toda la influencia española" (p.19). El autor usa categorias y adjetivaciones en oposiciones binarias sin gradaciones, como primitivismo/madurez de etnias nativas, el impulso civilizador de los conquistadores, el humanismo de los jesuitas frente a las hostilidades de las etnias aborígenes. El relato contiene conjeturas que no alcanzan el nivel de hipótesis, sin embargo construyen una narrativa que pretende verosimilitud.

El artículo cierra afirmando la certidumbre de que la labor compositiva e interpretativa de músicos argentinos emigrados en la segunda mitad del siglo XX al Hemisferio Norte no hacen sino "devolver en pequeña parte lo que Europa y Estados Unidos nos han dado" (p.52), encuadrándose nuevamente en las debatidas teorías que califican a Latinoamérica como un reflejo de la civilización europea.

De Melanie Plesch, "La lógica sonora de la generación del 80: una aproximación a la retórica del nacionalismo musical argentino" (pp. 55-108, el artículo de mayor extensión), se sitúa en una perspectiva postestructuralista diametralmente opuesta, donde la premisa es la revisión crítica de conceptos naturalizados en la historiografía musical tradicional.

En la introducción plantea claramente la meta y alcances de su investigación: en el campo del nacionalismo musical argentino, postula la idea de una "retórica musical de la argentinidad" para estudiar el repertorio de los compositores ochentistas. Es un concepto sólidamente construido y suficientemente problematizado por la autora como para superar sobradamente, en la interpretación de dicha música, "las estériles discusiones acerca de su eficacia estética o de su legitimidad como símbolo identitario" (p.57). Sus argumentaciones deductivo-inductivas llegan a resultados admirables.

El cuerpo del trabajo se estructura en tres partes que desarrollan y discuten minuciosamente cada uno de los presupuestos de la idea principal: la artificialidad de la retórica musical como discurso persuasivo y su pertinencia como herramienta analítica para este caso, la construcción histórico-política de los conceptos de "nacionalismo en general y de nacionalismo musical en particular" (p.57) y el consiguiente de identidad nacional.

En la primera parte, "De las naciones a los nacionalismos" argumenta sobre la idea de nación como una construcción discursiva de la modernidad, desarrollando las implicancias del programa socio-político que privilegió la "civilización" europea sobre la "barbarie" mestiza y criolla, la constitución de una identidad nacional hegemónica y homogeneizante, la fuerte incidencia socio-económica de la inmigración masiva y su amenaza para las clases dominantes, en tanto encarna el "nuevo epítome de la barbarie" (p.65). La "nostalgia" de un pasado menos conflictivo, que trae consigo la "alienación" y la "anonimia" urbanas en el contexto de la modernización, modifica la imagen ciudadana del gaucho -antes denigrada- y coadyuva a su idealización en la literatura criollista y la música nacionalista. Plesch reflexiona sobre la "apropiación", el "uso" y paradójicamente, el "distanciamiento" (lejanía, estilización del modelo musical rural) de la cultura popular, que realizaron las élites para construir símbolos de una pretendida identidad nacional. La autora nombra específicamente las canciones, danzas criollas y la guitarra como instrumento emblemático en la construcción de una retórica discursiva y musical del nacionalismo argentino.

En la segunda parte, "Nacionalismos musicales", para verificar la operación de consenso que convierte el 
nacionalismo musical en convención y artificio de carácter histórico, en contra de la idea esencialista de su naturalización, Plesch toma de Dahlhaus la idea de nacionalismo musical como resultado de la suma de intención del compositor más la recepción de la audiencia, así como el desvelamiento del carácter culturalmente situado -en la centralidad europea- de la pretendida universalidad de la música escrita occidental. La autora desarrolla lúcidamente la articulación del nacionalismo musical con el proyecto político de construcción de identidad nacional. Compara el Gato op.5 para guitarra de Juan Alais con El rancho abandonado de la suite En la Sierra op.32 de Alberto Williams, para revisar los calificativos de 'precursor' y 'la piedra fundamental' del nacionalismo musical argentino que respectivamente les atribuye la historiografía tradicional. Lo hace empleando las categorias de uso, intención, recepción y distanciamiento para analizar el grado de cercanía o alejamiento del modelo musical rural.

En la tercera parte, "La retórica musical del nacionalismo", Plesch aborda de lleno la teoría tópica y profundiza acerca del tratamiento de los topoi de la huella, la guitarra, la pentatonía y del triste / estilo, con variedad de ejemplos musicales tomados de Alberto Williams y Julián Aguirre.

Finalmente, bajo el subtítulo "Conclusiones" subraya la dimensión ideológica del nacionalismo musical argentino que articula poética y política, manifestándose como una construcción lógica que puede analizarse con las herramientas discursivas de la retórica. Advierte, además, que identificar y listar los topoi del nacionalismo musical no agota el análisis, sino que el verdadero desafío consiste en descubrir los "mundos de sentidos" a que estos refieren, como los valores, normas de comportamiento, creencias y jerarquías sociales, raciales que hacen a la cultura estudiada.

Luego de la lista de obras citadas en el texto, termina el artículo con un exhaustivo "Ensayo bibliográfico" que da cuenta de las fuentes bibliográficas y documentales que cimentaron el acabado pensamiento teórico-práctico de Melanie Plesch, el que, sin duda, resulta fecundo para nuevos desarrollos en la investigación musicológica.

Pola Suárez Urtubey, destacada musicóloga repetidamente premiada por su trayectoria y por sus investigaciones sólidamente documentadas, propone aquí "Medio siglo de creación musical argentina (19001950) (Proyectos y realidades)" (p.111-133), donde retoma su ya bastante conocida periodización por generaciones de compositores: "Primeros Profesionales" (A. Williams, J. Aguirre, A. Berutti); "La Generación del Ochenta"; "La generación del Centenario" y "La generación del 45". No queda claro cuál fue el criterio para definirlas, en tanto que la llamada Generación del ' 80 incluye a compositores nacidos entonces (entre 1875 y 1890), mientras que para las dos siguientes incluye a compositores cuya producción -y no su nacimiento- se enmarca en los años de la denominación. La exposición de ideas es muy clara y la redacción amena, cualidades que dejan fluir una lectura sostenida.

Es inevitable recordar la investigación de Plesch, en tanto hay subtemas superpuestos (la Generación del 80), pero el cotejo da divergencias teóricas y estéticas interesantes de señalar. El escrito de Suárez Urtubey se enmarca en el paradigma musicológico evolucionista que concibe la "creación musical argentina" como fruto de la asimilación progresiva de la "música culta europea". Luego de sus "crisis de crecimiento" (p.117) habría tendido a un "mayor grado de sincretismo" (p.121); el logro se escucharía en las obras tempranas de Ginastera por la incorporación del "acorde simbólico" y la fórmula rítmica del malambo (pp.121 y 132). Subyace entonces la selección propia de la historia de los "grandes compositores". La autora insiste en conceptos, esencialismos y naturalizaciones ya sometidos a crítica por Plesch, pocas páginas atrás para el lector, entre ellos "la búsqueda de un lenguaje que identifique al país", el nacionalismo de los ochentistas como "el entronque de lo folklórico argentino [...] con la música culta europea" (p.114) y "la esencia de lo vernáculo" que permanecería "como suave perfume" en el "lenguaje ideal" de Aguirre (p.116). Curiosamente coincide con Plesch en la elección de una cita de Williams (pp.72 y 116), pero aquí no figuran las fuentes de esta ni de las siguientes. Otra divergencia se da en cómo concibe el "indigenismo" o "incorporación de las tradiciones sonoras prehispánicas dentro de la producción culta" (p.118), dando por supuesto el conocimiento de la música precolombina por parte de los compositores argentinos. Desarrolla la recepción de las ideas de Ricardo Rojas en los músicos nacionalistas. Dedica la última sección a la heterogénea Generación del 45, donde diferencia subgrupos según sus afinidades estéticas.

A Federico Monjeau se le encomendó la reflexión sobre "lo europeo" en la música académica de la segunda mitad del siglo XX. Desde una perspectiva estética no exenta de las marcas de su notable profundización en la filosofía de T. W. Adorno, en "Anotaciones sobre la presencia europea en la música argentina contemporánea" (pp.135-149) Monjeau desarrolla la forma de procesar críticamente la tradición musical europea por parte de compositores argentinos cuidadosamente seleccionados. Ubica al compositor Francisco Kröpfl como un impulsor de las tendencias de avanzada a partir de la década de 1950, en Argentina y desde acá a Latinoamérica, a partir de su formación con Juan Carlos Paz y el contacto personal con vanguardistas europeos.

Después de la acción modernizadora del Grupo Renovación, la experiencia de Kröpfl con la música de Boulez y Stockhausen habría sido modélica para la actualización musical propuesta por el Centro Latinoamericano de Altos Estudios Musicales, que, a su vez, habría permitido la entrada en Buenos Aires de técnicas y pensamientos como los de Luigi Nono, lannis Xenakis, Bruno Maderna entre otros. Monjeau destaca la 
labor institucional de Kröpfl a favor de la formación de jóvenes compositores, como la fundación del Laboratorio de Fonología Musical (1958) y la dirección del Laboratorio de música electroacústica del CLAEM (1967), donde se abrió un espectro musical de "cosmopolitismo franco" (p.139). Mientras, Alberto Ginastera, fundador del CLAEM (incluido en el Instituto Di Tella de Buenos Aires), centro de formación y de amplísima irradiación vanguardista hacia el continente, se mantenía en una tradición algo diferente: "un intento de síntesis entre técnicas europeas avanzadas y materiales locales" (p.139).

Monjeau encuentra la especificidad de la música argentina de vanguardia de esa época en dos maneras, por lo que no fue (no nacionalista, no americanista, no experimental en el grado que lo desarrollaron otros departamentos del Instituto Di Tella) y por lo sí fue ("sustraída de la perspectiva nacionalista, autocentrada en su status académico y sin contacto con los géneros populares", p.140). El autor puntualiza que estas vanguardias participaron de la crisis de los 60 respecto del concepto adorniano de "material musical en evolución constante" (ib.) y luego, de la incitación a la "disponibilidad total" de los materiales históricos, "porque ella permitía reinterpretar la dialéctica de lo propio y de lo ajeno con entera libertad" (p.141). A partir de esta atractiva idea empleada por Monjeau para designar el uso y sistematización de citas musicales de la tradición europea, como una 'enciclopedia aplanada' a la que se puede entrar con total libertad, el autor analiza las operaciones de apropiación realizadas creativamente por Gerardo Gandini y Antonio Tauriello.

Otra línea vanguardista que Monjeau encuentra es la que abrió Mariano Etkin. Lector de la filosofía de Rodolfo Kush, Etkin reflexiona sobre la dialéctica del "ser" y del "estar" y establece una estética "no lineal, no narrativa y no sonatística" (p.143), que diverge de la "línea sonata-desarrollo"'. En su obra retoma la atención sobre la materia como hecho acústico antes que musical. Por último Monjeau destaca la forma musical de algunas de sus obras, plasmada a partir de su experiencia del recorrido del paisaje geográfico.

Osvaldo Golijov fue discípulo de Gandini y, si bien no compone en Argentina desde sus 23 años, Monjeau lo incluye en su selección de artistas prominentes, en este caso como representante de una cultura periférica, del multiculturalismo y compositor relevante de la música contemporánea para los estadounidenses. Exitoso en el mercado del arte, echa mano al eclecticismo musical, según Monjeau, sin filtrado y de manera directa.

Finalmente el autor dedica una sección a la vigencia de la ópera como 'otra marca de época' (148), género que comenzó como un apéndice de la ópera italiana en el país. La ópera en Argentina se mantuvo en la retaguardia de la actividad innovadora hasta el evento Bomarzo (1967-1972), que significó una 'actualización musical, dramática e ideológica'. Así, la ópera despertó el interés de jóvenes compositores y de las instituciones (Centro de Experimentación del Teatro Colón) y propone una presencia más dominante. Curiosa es la manera en que el autor olvida a Marta Lambertini, figura clave dentro del género y que sin duda alentó con su producción y sus enseñanzas el interés hacía él en destacados jóvenes compositores actuales.

En "Europa y el tango argentino. Intercambios culturales en el origen del tango" (pp.153-175), Pablo Kohan introduce con un relato ficcional una discusión no acabada sobre los orígenes del tango argentino. Usa este recurso literario para presentar la polifonía divergente de voces que nunca coincidieron sobre la génesis americana, europea o africana del género que califica como la "creación cultural argentina más original de la historia, la más reconocida en todo el mundo y la que ha contribuido con mayor significación al establecimiento de una identidad cultural y musical argentina" (p.157). Sin embargo, a pesar de su popularidad y de la pesada carga de representatividad que le atribuye, la única certidumbre respecto de su origen es una época aproximada, c. 1880, en ambas orillas del Río de la Plata.

Bajo el subtítulo "Tambores, fiestas y una danza" Kohan desglosa tres acepciones verosímiles de la etimología del término tango, para enlazar la tercera con el intercambio cultural que se estableció entre España y las colonias americanas (con ciertas imprecisiones históricas), proceso que generó el tango andaluz.

De alli sigue con un estudio centrado en las teorias sobre el origen, particularmente la de Carlos Vega y Alejo Carpentier. El énfasis en la teoría de Vega se debe a responder a la idea rectora de la publicación, es decir, las influencias europeas en la música argentina, y a que Vega sostuvo el origen español del tango argentino. Kohan discute con esta teoría a partir del conocimiento minucioso de los manuscritos y borradores mecanografiados del musicólogo, pues declara poseer una copia de los mismos confiada por la dirección del Instituto de Investigación Musicológica "Carlos Vega" de la Facultad de Artes y Ciencias Musicales de la Universidad Católica Argentina, donde, como se sabe, obra su archivo personal. Debemos recordar que los escritos inéditos de Vega referidos al origen del tango fueron publicados en 2007 por el Instituto que los resguarda, bajo el cuidado editorial de Coriún Aharonián.

Kohan coincide con Alejo Carpentier en descartar la génesis europea, y se concentra después en defender fervorosa e insistentemente el origen americano del tango. Finalmente dedica una sección a la migración y diáspora del género hacia Europa e Israel.

Del periodista y crítico Pablo Gianera se compila 'Crónica de un desencuentro afortunado. La música clásica europea en la literatura argentina' (pp.177-198). Meduloso artículo que pasa revista a los diferentes modos en que poetas, cuentistas y novelistas se relacionaron con la música. Pone de relieve la importancia de la música para muchos 
escritores, como un horizonte que debe perseguirse. Sin embargo, según T. S. Eliot, la poesía disminuye su condición estética cuando parodia a la música, aunque curiosamente recomienda el estudio de las formas y el ritmo musicales para el estudio de la poesía.

Gianera entiende que "la literatura argentina mantuvo una ambigua distancia respecto de la música clásica" (p.180), comparándola con las novelas de Tomas Mann o de Alejo Carpentier, que asumieron una arquitectura solicitada a las formas musicales. Argumenta que los escritores argentinos fueron "inmunes al discurso musical" (p.195), quizá por la "falta de frecuentación" con un instrumento, suposición que entra en contradicción con la presentación que el mismo autor hace de Juan Bautista Alberdi como pianista (p.181).

Fuera de estas apreciaciones, Gianera se ocupa de las relaciones entre literatura y música en textos de Echeverría, Leopoldo Lugones, Victoria Ocampo, Daniel Moyano, Manuel Mujica Láinez y Jorge Luis Borges, entre otros.

El libro sigue con la presentación de los autores mediante un breve curriculum vitae, un apéndice con referencias a la trayectoria y miembros del Mozarteum Jujuy, para finalizar con una lista de agradecimientos.

Me parece oportuno señalar que es curiosa la reincidencia en el tema del encuentro cultural entre Europa y Argentina, años después de su frecuentación y enconados debates historiográficos en ocasión del $V^{\circ}$ Centenario del primer arribo de Colón a América. Pese a ellos, a la vista está el interés renovado que suscita el tema en muchos intelectuales y artistas, por lo que el presente volumen constituye un aporte relevante a la historia de la música en Argentina y una nueva ocasión para el debate musicológico. El libro da cuenta de innumerables cuestionamientos, unos satisfactoriamente resueltos en algunos capítulos, otros no respondidos, y algunos, aún, descuidados. Con un nivel científico y/o reflexivo dispar en el abordaje de los temas, el volumen oscila entre un libro de divulgación y un libro científico. Evidencia la carencia de pautas iniciales dadas a los autores, fundamentalmente con respecto de las citas, textuales y bibliográficas, y de la profundidad y extensión de los capítulos. Se leen datos reproducidos de enfoques poco vigilados epistemológicamente junto a otros novedosos, altamente reflexivos y producidos a partir de la aplicación de teorías pertinentes.

Se han deslizado algunos errores por descuido en la edición, como las alteraciones en el ejemplo musical $n^{\circ}$ 4 (p.88), ciertas desprolijidades tipográficas (Linares en $p$. 82, topos en subtítulo, p.86, no en están en itálica; pero 'obras de salón', p.115, usa itálica innecesariamente), el apellido Berutti escrito de manera diferente ('Berutti', en el artículo de Plesch, pero 'Beruti' en el de Suárez Urtubey, aludiendo en ambos casos a Arturo Berutti), largas citas textuales en el cuerpo del artículo y no destacadas 'en caja' (p.116), entre otros detalles.

Lamentablemente, esta obra, como la mayoría de las ediciones de universidades nacionales argentinas, tiene una circulación sumamente restringida impresa en papel, debido a la deficiente distribución a través de las redes comerciales de libros. Sin embargo, puede leerse completa en http://issuu.com/valeabraham/docs/www. mozarteumjujuy.org.ar

Esto último facilita la divulgación inmediata del conocimiento producido por los intelectuales que, en este caso, resulta de interés para la musicología en el cono sur.

Fátima Graciela Musri es Profesora de Música especializada en Teorías Musicales, Magister en Arte Latinoamericano (U.N. de Cuyo) y en Historia (U.N. de San Juan). Ha cursado el Doctorado en Artes Mención Música (U.N. de Córdoba). Es Prof. Titular Efectiva de Historia de la Música y Coordinadora del Gabinete de Estudios Musicales en la U.N. de San Juan donde dirige proyectos, investigadores y becarios. Ha integrado jurados de concursos docentes, comités de lectura y de evaluación de pares a nivel nacional. Publicó artículos en revistas especializadas y los libros: Músicos inmigrantes. La familia Colecchia en la actividad musical de San Juan (1880-1910) y Reconstrucción de los espacios socio-musicales en San Juan (1944-1970), por la Editorial de la Facultad de Filosofía, Humanidades y Artes de la U.N. de San Juan. Ha coeditado el $n^{\circ} 7$ de la Revista Argentina de Musicología de la AAM. Produjo el CD Músicos abruzenses en San Juan, videos documentales y programas radiales. Es integrante como investigadora formada del proyecto Nacionalismos y vanguardias musicales en Argentina, dirigido por Silvina Luz Mansilla (UBA). 